\title{
(6) OPEN ACCESS \\ Randomised controlled trial of video clips and interactive games to improve vision in children with amblyopia using the I-BiT system
}

\author{
Nicola Herbison, ${ }^{1}$ Daisy MacKeith, ${ }^{2}$ Anthony Vivian, ${ }^{2}$ Jon Purdy, ${ }^{3}$ Apostolos Fakis, ${ }^{4}$ \\ Isabel M Ash, ${ }^{1}$ Sue V Cobb, ${ }^{5}$ Richard M Eastgate, ${ }^{5}$ Stephen M Haworth, ${ }^{6}$ \\ Richard M Gregson, ${ }^{6}$ Alexander JE Foss ${ }^{1}$
}

- Additional material is published online only. To view, please visit the journal online (http://dx.doi.org/10.1136/ bjophthalmol-2015-307798)

${ }^{1}$ Department of

Ophthalmology, Nottingham University Hospitals,

Nottingham, UK

${ }^{2}$ Department of

Ophthalmology, Addenbrooke's

Hospital, Cambridge, UK

${ }^{3}$ Department of Computer

Science, University of Hull, Hull, UK

${ }^{4}$ Derby Clinical Trials Unit, College of Health and Social Care, University of Derby, Derby, UK

${ }^{5}$ Department of Mechanical, Materials and Manufacturing Engineering, University of Nottingham, Nottingham, UK ${ }^{6}$ Department of

Ophthalmology, Nottingham University Hospitals,

Nottingham, UK*

\section{Correspondence to} Professor Alexander JE Foss, Department of Ophthalmology, Queen's Medical Centre, Nottingham NG7 2UH, UK; alexander.foss@nottingham.ac.

*Previous address, now retired.

Received 7 September 2015 Revised 5 December 2015 Accepted 25 January 2016 Published Online First

7 March 2016

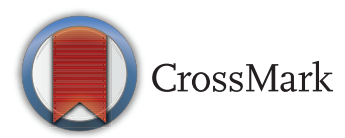

To cite: Herbison $\mathrm{N}$, MacKeith D, Vivian A, et al. $\mathrm{Br} J$ Ophthalmol

2016:100:1511-1516.

\section{ABSTRACT}

Background Traditional treatment of amblyopia involves either wearing a patch or atropine penalisation of the better eye. A new treatment is being developed on the basis of virtual reality technology allowing either DVD footage or computer games which present a common background to both eyes and the foreground, containing the imagery of interest, only to the amblyopic eye.

Methods A randomised control trial was performed on patients with amblyopia aged 4-8 years with three arms. All three arms had dichoptic stimulation using shutter glass technology. One arm had DVD footage shown to the amblyopic eye and common background to both, the second used a modified shooter game, Nux, with sprite and targets presented to the amblyopic eye (and background to both) while the third arm had both background and foreground presented to both eyes (non-interactive binocular treatment (non-I-BiT) games). Results Seventy-five patients were randomised; 67 were residual amblyopes and 70 had an associated strabismus. The visual acuity improved in all three arms by approximately $0.07 \log M A R$ in the amblyopic eye at 6 weeks. There was no difference between I-BiT DVD and non-I-BiT games compared with I-BiT games (stated primary outcome) in terms of gain in vision.

Conclusions There was a modest vision improvement in all three arms. Treatment was well tolerated and safe. There was no difference between the three treatments in terms of primary stated outcomes but treatment duration was short and the high proportion of previously treated amblyopia and strabismic amblyopia disadvantaged dichoptic stimulation treatment.

Trial registration number NCT01702727, results.

\section{INTRODUCTION}

The mainstay of treatment for amblyopia caused by anisometropia or strabismus, after correction of refractive error, is occlusion, by patching, of the normal eye. This idea of 'forcing' the amblyopic eye to see dates at least as far back as de Buffon. ${ }^{1}$ There is a sensitive period for the development of the visual system during which patching is effective. It is more effective for younger children but a randomised control trial of patching has shown that about half of children with amblyopia in the 712 year age range will respond to optical treatment and patching. ${ }^{2}$ Some children over the age of 12 years also improved but only if they had not received previous treatment. ${ }^{2}$
The additive effect of patching after spectacle adaptation is modest. A randomised control trial of patching in children who had 16 weeks of full refractive correction gained a further 1.3 lines in the control group (spectacle correction alone can continue to improve vision for up to 30 weeks) and 2.2 lines in those who had $2 \mathrm{~h}$ of patching per day. ${ }^{3}$ The effectiveness of patching depends upon the degree of amblyopia with little benefit for those with mild levels of amblyopia (6 September-6 December). ${ }^{4}$ In the $1850 \mathrm{~s}$, Javal introduced atropine penalisation which is as effective as patching ${ }^{5-8}$ and the two treatments are not additive-nothing is to be gained by combining them. ${ }^{9}$

Current treatments are only moderately effective with amblyopia persisting beyond the age of 16 years in $80 \%$ of patients. ${ }^{10}$ A further drawback shared by both patching and penalisation is that they are 'dissociative' and do nothing to encourage the amblyopic and the normal eye to work in harmony together. Furthermore, compliance with patching is often poor with up to $50 \%$ of patients not complying with the prescribed dosage, ${ }^{11}$ suggesting that the treatment is not popular with children. There is clearly a need for something better.

These considerations led us to develop a virtual reality-based system $^{12}$ to treat amblyopia using dichoptic stimulation in the context of either playing special video games or watching DVDs. This interactive binocular treatment (I-BiT) system uses specially configured software to preferentially stimulate the amblyopic eye without compromising the vision in the good eye.

Three pilot studies ${ }^{13-15}$ have shown the I-BiT system can improve the visual acuity in patients with amblyopia. The most recent of these pilot studies using shutter glasses technology ${ }^{15}$ showed that all patients who completed their planned treatment (9 of the 10 patients) showed an improvement in visual acuity from 0.025 to $0.45 \log$ MAR units with a mean of 0.18 (SD 0.14).

On the basis of these results, we decided to proceed to a small two centre randomised control trial with the intention of ensuring that the treatment was safe, acceptable and to get an improved indication of its efficacy.

\section{MATERIALS AND METHODS}

Trial design

The full trial design and protocol is available from a previous publication. ${ }^{16}$ 
The study was a randomised parallel group design with the intention to recruit 75 patients. The eligible patients were randomised to one of three treatments.

- I-BiT game

- Non-I-BiT game

- I-BiT DVD.

Each received their randomised treatment weekly for 6 weeks, for a 30 min period.

At baseline their logMAR visual acuity, with glasses if required, was recorded along with the results of their cover test, oculomotility assessment, binocular vision assessment, visuoscope and Sbisa bar results.

Visual acuity was assessed pretreatment (week 1), after three treatments (week 3), after six treatments (week 6) and 4 weeks after their final treatment (week 10). Visual acuity was assessed with either the logMAR crowded test (formally Glasgow acuity cards, manufactured by Keeler) or the crowded Kay's picture test. Choice of visual acuity (VA) test was dependent on the participant's ability and remained consistent throughout the trial.

\section{Participants and recruitment}

Children aged 4-8 years with strabismic, anisometropic or mixed amblyopia were recruited from two test sites (Queen's Medical Centre, Nottingham and Addenbrooke's Hospital,
Cambridge), from January 2012 to November 2013. Stimulus deprivation amblyopia was excluded.

Children who had prior treatment with either patching or atropine penalisation were eligible for recruitment providing they had a $0.20 \log$ MAR intraocular acuity difference and no current improvement with patching. Those whose suppression measured four or less on the Sbisa bar were deemed at risk of double vision and were excluded. For full list of inclusion and exclusion criteria, see the protocol paper. ${ }^{16}$

\section{Interventions}

I-BiT shutter glasses system

The I-BiT system hardware is designed for use under supervision and consists of a desktop PC with two monitors, one for the clinician and one for the patient. The clinician monitor is used to control the treatment the patient receives and the patient monitor displays the visual stimuli. The patient monitor is a flat-screen 22-inch 3D monitor with a refresh rate of $120 \mathrm{~Hz}$ and this allows separate images to be presented to each eye with the use of shutter glasses. The shutter glass lenses lighten and darken in synchrony with the monitor but faster than the user can perceive and this allows a common background to be presented to both eyes and an 'enriched' image to be presented only to the amblyopic eye (dichoptic stimulation). The I-BiT
Figure 1 The Consolidated Standards of Reporting Trials (CONSORT) flow diagram for the trial.

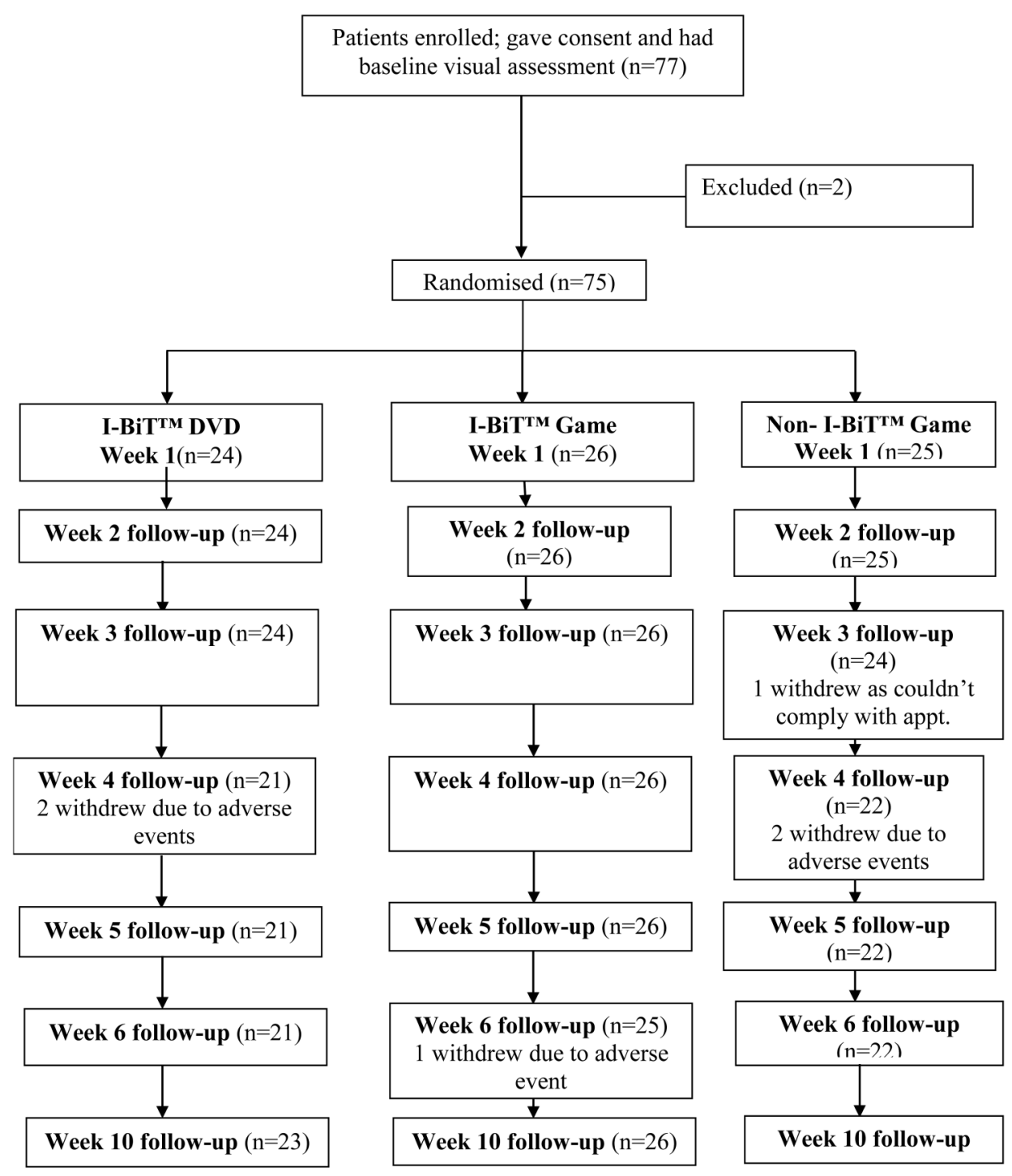


system can display video footage and interactive games. A gaming control pad is used for the games.

\section{DVD stimulus}

The I-BiT DVD stimulus is divided into two zones. There is an outer 'border' termed a locking stimulus which is presented to both eyes while the inner part of the screen presents the video footage predominately to the amblyopic eye.

\section{Game stimulus}

An interactive game called 'Nux' was used to provide the game play. Through the I-BiT system, the player and the background are shown to both eyes but the obstacles, enemies and coins are shown only to the amblyopic eye. Therefore, in order for the child to play the game successfully, they must use their amblyopic eye.

\section{Control stimulus}

In the non-I-BiT game version (control arm) both eyes receive identical stimulation.

\section{Outcomes}

The primary objectives of the study were:

1. To determine the difference in visual acuity improvement in patients treated with I-BiT compared with non-I-BiT treatment.

2. To determine the difference in effectivity between the interactive games and DVDs.

The primary outcome measure was the change in logMAR visual acuity from week 1 (pretreatment) to week 6 (post-treatment).

The secondary outcome measures included changes in stereoacuity (Frisby test), and the safety, acceptability and compliance of treatment.

Loss of visual acuity of $0.1 \log$ MAR units at week 3 or double vision induced withdrawal from the trial.

\section{Sample size}

The sample size of 75 patients (25 in each arm) was calculated assuming an SD of 0.25 with the aim to detect a minimum difference of $0.2 \log$ MAR units at the $5 \%$ significance level (twosided) with $80 \%$ power.

\section{Randomisation}

The randomisation sequence was generated using the RALLOC function in Stata V.10 and used random permuted blocks of sizes 2, 4 and 6. It was stratified by centre and whether or not the patient had previous treatment for amblyopia.

\section{Masking}

The research orthoptist who delivered the treatment was aware of the patient allocation but not of visual acuity measurements which were performed by an independent orthoptist who was masked to the treatment allocation.

\section{Statistical methods}

Data analysis was performed using Stata V.11.2. Intention to treat analysis was performed for the primary outcome. All missing data were assumed to be missing completely at random and imputation methods were not used to compensate for missing data.

The primary endpoint of change in visual acuity from week 1 to end of treatment (week 6) was compared between the treatment groups using Analysis of Covariance (ANCOVA) with baseline visual acuity as covariate. The change in visual acuity from week 1 to week 3 and 10 was compared between the treatment groups using ANCOVA with baseline visual acuity as covariate. Difference within groups from baseline to 3, 6 and 10 weeks post-treatment was tested for using a two-tailed paired $\mathrm{t}$ test. The proportion of patients showing a clinically important change in VA $(\geq 0.125 \log \mathrm{MAR})$ from baseline at 3,6 and 10 weeks was compared between the three groups using Fisher's exact test. The frequency (\%) of patients' satisfaction, compliance with treatment and adverse events were also analysed.

Unplanned secondary analyses of the change in VA for all participants from baseline to weeks 3, 6 and 10 were performed using a paired test.

\section{Ethical review}

This study was approved by Nottingham Research Ethics Committee 2.

\section{RESULTS}

\section{Participant flow and baseline data}

The patient flow is summarised in the Consolidated Standards of Reporting Trials (CONSORT) diagram (figure 1) and the baseline data in table 1 and further baseline data can be found in the online supplementary file.

The visual acuity improved in all three groups at weeks 3, 6 and 10 with the average improvement of vision at week 6 of

Table 1 Summary of baseline characteristics of the study population

\begin{tabular}{|c|c|c|c|}
\hline & I-BiT DVD & I-BiT games & Non-I-BiT games \\
\hline Number randomised & 24 & 26 & 25 \\
\hline Mean (SD) age (years) & $5.9(1.2)$ & $6.0(1.3)$ & $5.6(1.1)$ \\
\hline \multicolumn{4}{|l|}{ Gender } \\
\hline Male (\%) & $13(54 \%)$ & $17(65 \%)$ & $13(52 \%)$ \\
\hline Female (\%) & $11(46 \%)$ & $9(35 \%)$ & $12(48 \%)$ \\
\hline \multicolumn{4}{|l|}{ Experience with computer games } \\
\hline Does not play & 3 & 5 & 4 \\
\hline$<30 \mathrm{~min} /$ day & 12 & 7 & 12 \\
\hline 30-60 min/day & 6 & 10 & 4 \\
\hline 1-2 h/day & 2 & 4 & 3 \\
\hline$>2$ h/day & 1 & 0 & 2 \\
\hline \multicolumn{4}{|l|}{ Type of amblyopia } \\
\hline Strabismic & 13 & 6 & 5 \\
\hline Mixed & 11 & 17 & 18 \\
\hline Anisometropic & 0 & 3 & 2 \\
\hline \multicolumn{4}{|l|}{ Previous amblyopia treatment } \\
\hline Yes & 19 & 20 & 18 \\
\hline Occlusion & 19 & 20 & 17 \\
\hline Penalisation & 4 & 3 & 7 \\
\hline None & 5 & 6 & 7 \\
\hline \multicolumn{4}{|c|}{ Acuity in amblyopic eye at baseline (logMAR) } \\
\hline Mean & 0.53 & 0.49 & 0.50 \\
\hline Range & $0.36-0.65$ & $0.38-0.55$ & $0.35-0.65$ \\
\hline SD & 0.21 & 0.17 & 0.20 \\
\hline \multicolumn{4}{|l|}{ Fixation with amblyopic eye } \\
\hline Foveolar & 3 & 1 & 2 \\
\hline Parafoveolar & 5 & 11 & 4 \\
\hline Parafoveal & 8 & 5 & 2 \\
\hline Eccentric & 4 & 1 & 2 \\
\hline No view with amblyoscope & 4 & 8 & 15 \\
\hline
\end{tabular}


Table 2 Improvement in vision for all the patients in the trial

\begin{tabular}{llll}
\hline & $\begin{array}{l}\text { Improvement in } \\
\text { logMAR vision }\end{array}$ & Cls & p Value \\
\hline Baseline and week 3 & -0.04 & -0.63 to -0.20 & $<0.001$ \\
Baseline and week 6 & -0.07 & -0.11 to -0.047 & $<0.0001$ \\
Baseline and week 10 & -0.067 & -0.097 to 0.038 & $<0.0001$ \\
\hline Significance testing was performed using a paired t test and probability values \\
calculated on the basis of two-tailed.
\end{tabular}

$0.07 \log$ MAR which was sustained at week 10 . This improvement was significant at all three time points (using paired t tests, $\mathrm{p}<0.001$ at all three time points) (table 2).

\section{The primary outcome}

The primary outcome measure was the difference in visual acuity improvement between the three arms at week 6 with I-BiT games as the comparison arm. The change in visual acuity from baseline to the end of treatment (week 6) is shown in table 3 .

There was no difference in the change from baseline between those having I-BiT games and those having non-I-BiT games (mean $0.02 \log$ MAR units $95 \%$ CI (-0.07 to 0.03$)$ ). The improvement in vision from baseline at 6 weeks differed between the two games treatment groups and the DVD group, with a mean of change in the I-BiT DVD group of -0.1 compared with -0.06 in the I-BiT games group and -0.03 in the non-I-BiT games group.

\section{Secondary outcomes}

The change in vision at weeks 3 and 10, and the proportion of patients with a clinically significant improvement (defined as $\geq 1.25 \log$ MAR units) are summarised in table 3 .

There were no significant improvements in stereoacuity (Frisby) in the three arms (see online supplementary material).

The I-BiT DVD and non-I-BiT game improved vision to week 6 then declined slightly after treatment finished (week 10). The I-BiT games group increased from weeks 3-6 and then a decrease to week 10 . The mean VA at week 10 was less than baseline for all three groups.

The patient satisfaction questionnaire showed that $>90 \%$ of participants felt that they enjoyed their treatment, $>80 \%$ felt that the time allowed was just right, and that $67 \%$ or more felt that it was easy to concentrate.

Compliance with each of the treatments was excellent with the majority of participants playing the game/watching the DVD for $30 \mathrm{~min}$ at each session.

\section{Adverse events}

These are summarised in table 4. There were two cases of double vision which were assumed to be adverse device effects

Table 3 Summary of outcomes

\begin{tabular}{|c|c|c|c|}
\hline & I-BiT DVD & I-BiT games & Non-I-BiT games \\
\hline Number randomised & 24 & 26 & 25 \\
\hline \multicolumn{4}{|l|}{ Primary outcome } \\
\hline \multicolumn{4}{|l|}{ Change from baseline to week 6 in visual acuity (logMAR) } \\
\hline $\mathrm{N}$ & 21 & 25 & 22 \\
\hline Mean (SD) & $-0.1(0.02)$ & $-0.06(0.02)$ & $-0.03(0.02)$ \\
\hline Median (range) & $-0.1(-0.15,0.05)$ & $-0.05(-0.13,0)$ & $-0.04(-0.1,0.04)$ \\
\hline \multicolumn{4}{|l|}{ Difference from I-BiT games } \\
\hline Mean (SE) & $0.05(0.03)$ & & $0.02(0.03)$ \\
\hline $95 \% \mathrm{Cl}$ & -0.004 to 0.10 & & -0.07 to 0.03 \\
\hline $\mathrm{p}$ Value (from ANCOVA with baseline VA as covariate) & 0.067 & & 0.429 \\
\hline \multicolumn{4}{|l|}{ Secondary outcomes } \\
\hline \multicolumn{4}{|l|}{ Change in VA from baseline to week 10} \\
\hline \multicolumn{4}{|l|}{ Change from baseline to week 10 in visual acuity (logMAR) } \\
\hline $\mathrm{N}$ & 23 & 26 & 24 \\
\hline Mean (SE) & $-0.07(0.03)$ & $-0.07(0.03)$ & $-0.06(0.02)$ \\
\hline Median (IQR) & $-0.08(-0.18,-0.02)$ & $-0.09(-0.16,-0.07)$ & $-0.05(-0.15,0)$ \\
\hline \multicolumn{4}{|l|}{ Difference from I-BiT games } \\
\hline Mean (SE) & $0.003(0.04)$ & & $-0.01(0.04)$ \\
\hline $95 \% \mathrm{Cl}$ & -0.07 to 0.07 & & -0.08 to 0.06 \\
\hline \multicolumn{4}{|l|}{ Change in VA from baseline to week 3} \\
\hline \multicolumn{4}{|l|}{ Change from baseline to week 3 in visual acuity (logMAR) } \\
\hline $\mathrm{N}$ & 24 & 26 & 24 \\
\hline Mean (SD) & $-0.05(0.02)$ & $-0.05(0.02)$ & $-0.02(0.02)$ \\
\hline Median (IQR) & $0.07(-0.12,-0.005)$ & $-0.04(-0.1,0.008)$ & $-0.03(-0.08,0.02)$ \\
\hline \multicolumn{4}{|l|}{ Difference from I-BiT games } \\
\hline Mean (SE) & $0.002(0.03)$ & & $-0.03(0.02)$ \\
\hline $95 \% \mathrm{Cl}$ & -0.06 to 0.06 & & -0.08 to 0.01 \\
\hline \multicolumn{4}{|c|}{ Proportion (\%) of patients showing a clinically important change in VA ( $\geq 1.25 \log M A R)$} \\
\hline Week 3 & $6(25 \%)$ & $4(15 \%)$ & $1(4 \%)$ \\
\hline Week 6 & $6(25 \%)$ & $6(23 \%)$ & $4(16 \%)$ \\
\hline Week 10 & $10(42 \%)$ & $11(42 \%)$ & $8(32 \%)$ \\
\hline
\end{tabular}


Table 4 Summary of adverse events in the trial

\begin{tabular}{lcll}
\hline & $\begin{array}{l}\text { I-BiT DVD } \\
\text { N=24 }\end{array}$ & $\begin{array}{l}\text { I-BiT game } \\
\mathbf{N = 2 6}\end{array}$ & $\begin{array}{l}\text { Non-I-BiT game } \\
\text { N=25 }\end{array}$ \\
\hline $\begin{array}{l}\text { Adverse events leading to withdraw from trial } \\
\text { Double vision }\end{array}$ & 1 & 1 & \\
$\quad$ Drop in vision & 2 & 0 & 2 \\
Adverse events not leading to withdraw & & \\
$\quad$ Flu or cough & 2 & 2 & 2 \\
Tonsillitis & 1 & 0 & 1 \\
Conjunctivitis & 1 & 0 & \\
Diarrhoea and/or vomiting & 0 & 6 & 2 \\
Other infection & 0 & 1 & 0 \\
Eczema & 1 & 0 & 1 \\
Trauma & 1 & 0 & 1 \\
Eye feeling funny & 1 & 0 & 0 \\
\hline
\end{tabular}

and they both resolved spontaneously following cessation of treatment. All other adverse events are assumed to be not device related.

\section{DISCUSSION}

There was a modest visual acuity improvement in all groups including group 3 who received the non-I-BiT game. The visual acuity improvement of $0.07 \operatorname{logMAR}$ is less than the 0.18 which we had observed previously but is similar to the 0.1 improvement reported by $\mathrm{Li}$ et al. ${ }^{17}$ It was an unexpected finding that the non-I-BiT game showed some improvement in visual acuity and the reason is not clear. It is possible that use of the shutter glasses alone may have improved amblyopic vision. The control group had all of the game content shown to both eyes but because of the shutter glasses it is, in reality, only shown to one eye at a time. The shutter glasses operate fast enough that the game content is perceived by both eyes simultaneously. Dichoptic stimulation may itself improve vision without the use of 'preferential stimulation' of the amblyopic eye which occurred in the I-BiT game and I-BiT DVD groups.

The study was disadvantaged by the fact that the majority of participants in this trial (67/75) were residual amblyopes (conventional patching failures) and there was a high proportion of strabismic amblyopia (70/75). This represents a poor prognostic group but the decision to allow previous amblyopia treatment failures into the trial was based on the fact that they were far easier and quicker to recruit. Another limiting factor was that the treatment in this trial was hospital based during working and school hours which limited the duration and frequency of treatment sessions to only half an hour a week. The total treatment time of only $3 \mathrm{~h}$ is very short when compared with patching where the Monitored Occlusion Treatment of Amblyopia (MOTAS) group recommended at least $150 \mathrm{~h}$ and showed a linear response for up to $400 \mathrm{~h} .{ }^{18}$ The study by Li et al used an I-Pad delivery system with $16 \mathrm{~h}$ of game play $>4$ weeks and with no extra benefit from a further $16 \mathrm{~h}$ over a further 4 week period. ${ }^{17}$ Hess's group, using an I-Pad at home ${ }^{19}$ showed that 1-2 h per day for 1-3 weeks can improve acuity, restore binocularity and restore stereopsis in adults. ${ }^{20}$ Vedamurthy et al also developed a dichoptic action videogame and with $40 \mathrm{~h}$ of treatment in adults showed improvements in both anisometropic and strabismic amblyopes of logMAR $0.14 .^{21}$

There were two classes of adverse events that lead to patient withdrawal diplopia and reduction visual acuity Double vision is presumed to be due to the treatment reversing suppression and was considered a device-related adverse event and the two cases resolved fully on cessation of treatment. No adverse events have been reported by other groups.

Patching and penalisation are not popular treatments and systematic reviews have suggested that the impact on health-related quality of life for patients with amblyopia comes from the treatment rather than the disease. ${ }^{22} 23$ This dichoptic stimulation treatment was very acceptable and with a compliance rate of $>90 \%$, much better than the $48 \%$ reported for patching. ${ }^{24}$ Others have also noted the high acceptability of computer games as a vehicle for treatment. ${ }^{25}$ Amblyopia often coexists with strabismus and 70 of the 75 patients in this trial had manifest strabismus. Failure of the amblyopic eye to become the fixating eye may prevent dichoptic stimulation being an effective treatment in patients with strabismus unless the stimulus can be delivered to the fovea.

There was some improvement in vision in all three groups after a total of $3 \mathrm{~h}$ of treatment which was well tolerated and safe. There was no apparent advantage to differential targeting of the amblyopic eye with dichoptic stimulation. However, the short total treatment time, high proportion of previous amblyopia treatment failures and high proportion of patients with strabismus disadvantage dichoptic stimulation and this study does not suggest that a treatment benefit is not achievable. Further studies are being targeted at longer treatment duration (requiring a home-based treatment), naïve amblyopes and a greater proportions of anisometropic amblyopes to determine whether the I-BiT system has the potential to deliver a treatment for amblyopia which is more acceptable and equally or more effective than conventional treatment.

Contributors RMG was the principal investigator who conceived and designed the study. He retired prior to commencement of this trial and AJEF took over as chief investigator and principal investigator for the Nottingham site and oversaw delivery. $\mathrm{AV}$ was the principal investigator for the Cambridge site. NH was project manager and research orthoptist at the Nottingham site. DMK was research orthoptist at both the Nottingham and Cambridge site. JP had responsibility for the programming. SVC and RME helped both design and maintain the equipment. AF was the trial statistician and undertook the analyses. SMH was a member of the project steering group. This manuscript was drafted by AJEF, revised by AV and approved by all living authors.

Funding The work in this study was funded by the Wellcome Trust (Translation Award 090465).

Competing interests AJEF reports that Nottingham University Hospitals Trust and Nottingham University own the rights to an European patent EP 1509121 B1. My coauthors include IMA, SVC, RME, RMG and SMH who are included in the list of inventors.

Ethics approval Nottingham Research Ethics Committee 2.

Provenance and peer review Not commissioned; externally peer reviewed.

Data sharing statement Unpublished data are available upon request.

Open Access This is an Open Access article distributed in accordance with the terms of the Creative Commons Attribution (CC BY 4.0) license, which permits others to distribute, remix, adapt and build upon this work, for commercial use, provided the original work is properly cited. See: http://creativecommons.org/licenses/ by/4.0/

\section{REFERENCES}

1 de Buffon L. Bull Mém Acad Sci Paris 1743;Suppl III:174.

2 Scheiman MM, Hertle RW, Beck RW, et al. Pediatric Eye Disease Investigator Group. Randomized trial of treatment of amblyopia in children aged 7 to 17 years. Arch Ophthalmol 2005;123:437-47.

3 Wallace DK, Pediatric Eye Disease Investigator Group. A randomized trial to evaluate 2 hours of daily patching for strabismic and anisometropic amblyopia in children. Ophthalmology 2006;113:904-12. 
4 Clarke MP, Wright CM, Hrisos S, et al. Randomised controlled trial of treatment of unilateral visual impairment detected at preschool vision screening. BMJ 2003;327:1251.

5 Foley-Nolan A, McCann A, O'Keefe M. Atropine penalisation versus occlusion as the primary treatment for amblyopia. $\mathrm{Br} J$ Ophthalmol 1997:81:54-7.

6 Repka MX, Wallace DK, Beck RW, et al. Two-year follow-up of a 6-month randomized trial of atropine vs patching for treatment of moderate amblyopia in children. Arch Ophthalmol 2005;123:149-57.

7 Tejedor J, Ogallar C. Comparative efficacy of penalization methods in moderate to mild amblyopia. Am J Ophthalmol 2008;145:562-9.

8 Medghalchi AR, Dalili S. A randomized trial of atropine vs patching for treatment of moderate amblyopia. Iran Red Crescent Med J 2011;13:578-81.

9 Pediatric Eye Disease Investigator Group (PEDIG) Writing CommitteeWallace DK, Kraker RT, et al. Randomized trial to evaluate combined patching and atropine for residual amblyopia. Arch Ophthalmol 2011;129:960-2.

10 Rahi JS, Cumberland PM, Peckham CS. Does amblyopia affect educational, health, and social outcomes? Findings from 1958 British birth cohort. BMJ 2006;332:820-5

11 Wallace MP, Stewart CE, Moseley MJ, et al. Compliance with occlusion therapy for childhood amblyopia. Invest Ophthalmol Vis Sci 2013;54:6158-66.

12 Easgate RM, Griffiths GD, Waddingham PE, et al. Modified virtual reality technology for treatment of amblyopia. Eye (Lond) 2006;20:370-4.

13 Cleary M, Moody AD, Buchanan A, et al. Assessment of a computer-based treatment for older amblyopes: the Glasgow Pilot Study. Eye (Lond) 2009:23:124-31.

14 Waddingham PE, Butler TK, Cobb SV, et al. Preliminary results from the use of the novel interactive binocular treatment (I-BiT) system, in the treatment of strabismic and anisometropic amblyopia. Eye (Lond) 2006;20:375-8.
15 Herbison N, Cobb S, Gregson R, et al. Interactive binocular treatment (I-BiT) for amblyopia: results of a pilot study of 3D shutter glasses system. Eye (Lond) 2013;27:1077-83.

16 Foss AJ, Gregson RM, MacKeith D, et al. Evaluation and development of a novel binocular treatment (I-BiTTM) system using video clips and interactive games to improve vision in children with amblyopia ('lazy eye'): study protocol for a randomised controlled trial. Trials 2013;14:145.

17 Li SL, Jost RM, Morale SE, et al. A binocular iPad treatment for amblyopic children. Eye (Lond) 2014;28:1246-53.

18 Stewart CE, Stephens DA, Fielder AR, et al. MOTAS Cooperative. Modeling dose-response in amblyopia: toward a child-specific treatment plan. Invest Ophthalmol Vis Sci 2007:48:2589-94.

19 To L, Thompson B, Blum JR, et al. A game platform for treatment of amblyopia. IEEE Trans Neural Syst Rehabil Eng 2011;19:280-9.

20 Hess RF, Thompson B, Black JM, et al. An iPod treatment for amblyopia: an updated binocular approach. Optometry 2012;15:87-94.

21 Vedamurthy I, Nahum M, Huang SJ, et al. A dichoptic custom-made action video game as a treatment for adult amblyopia. Vision Res 2015;114:173-87.

22 Carlton J, Kaltenthaler E. Amblyopia and quality of life: a systematic review. Eye (Lond) 2011;25:403-13.

23 Carlton J, Kaltenthaler E. Health-related quality of life measures (HRQOL) in patients with amblyopia and strabismus: a systematic review. $\mathrm{Br} J$ Ophthalmol 2011;95:325-30.

24 Stewart CE, Moseley MJ, Stephens DA, et al., MOTAS Cooperative. Treatment dose-response in amblyopia therapy: the Monitored Occlusion Treatment of Amblyopia Study (MOTAS). Invest Ophthalmol Vis Sci 2004;45:3048-54.

25 Tailor VK, Glaze S, Khandelwal P, et al. Prescribed computer games in addition to occlusion versus standard occlusion treatment for childhood amblyopia: a pilot randomised controlled trial. Pilot Feasab Stud 2015;1:23. 